Research Article

\title{
4D Trajectory Planning of Aircraft Taxiing considering Time and Fuel
}

\author{
Ningning Zhao $\mathbb{D}^{1},{ }^{1}$ Nan $\mathrm{Li}^{1}{ }^{1}$ Yu Sun, ${ }^{1}$ and Zheng Gao ${ }^{2}$ \\ ${ }^{1}$ College of Air Traffic Management, College of Air Traffic Management, Tianjin 300300, China \\ ${ }^{2}$ Tianjin Air Traffic Management Bureau, Civil Aviation Administration of China, Tianjin 300300, China
}

Correspondence should be addressed to Ningning Zhao; xianyuer315@163.com

Received 5 July 2020; Revised 7 October 2020; Accepted 20 November 2020; Published 9 December 2020

Academic Editor: Antonios Tsourdos

Copyright $($ C 2020 Ningning Zhao et al. This is an open access article distributed under the Creative Commons Attribution License, which permits unrestricted use, distribution, and reproduction in any medium, provided the original work is properly cited.

Most of the traditional taxi path planning studies assume that the aircraft is in uniform speed, and the model is optimized based on the shortest taxi time. Although it is easy to solve, it does not consider the change of the speed profile when the aircraft turns, and the optimal taxiing time of the aircraft does not necessarily bring the optimal taxiing fuel consumption. In this paper, the aircraft's taxi distance and the number of turns in the taxi are considered. The aircraft path planning model with the shortest total distance of the airport surface is established. The improved $\mathrm{A}^{*}$ algorithm is used to obtain the shortest path P. Based on this, the shortest path $\mathrm{P}$ is established. Considering the multitarget velocity profile model of time and fuel consumption, a heuristic search is used to generate an accurate velocity profile for each path to obtain a $4 \mathrm{D}$ trajectory of the aircraft and then quantitative analysis of the impact of aircraft pollutant emissions on the airport environment based on $4 \mathrm{D}$ trajectory taxi time. The experimental results show that, compared with the traditional optimization method without considering the turning times, the total taxiing distance and turning times of the aircraft are greatly reduced. By balancing the taxiing time and fuel consumption, a set of Pareto-optimal velocity profiles is generated for the aircraft taxiing path; at the same time, it will help the airport save energy and reduce emissions and improve the quality of the airport environment. It has a high practical application value and is expected to be applied in the real-time air traffic control decision of aircraft surface in the future.

\section{Introduction}

With the rapid development of the air transport industry, the flight volume of major airports in China is increasing, which makes the airport surface congested, especially causing the aircraft at the airport surface to take too long to taxi, and the runway entrances are queuing up to wait for the number of departing flights, resulting in the work of controllers being overloaded, which seriously threatens the taxiing safety of the aircraft. Due to the conflict or crowded waiting of aircraft at the airport surface, each additional 1 min of taxi time will increase the fuel consumption by $10-20 \mathrm{~kg}[1,2]$, resulting in an increase in aircraft exhaust emissions and affecting the quality of air around the airport. For the sustainable development of air transportation, scientific and efficient taxi path planning methods are adopted, which can not only reduce the taxi time and fuel consumption of aircraft at the airport surface but also ensure the reliability and safety of actual airport operations and improve the safety and security of scene operations.

Many scholars at home and abroad have studied the taxiing path and $4 \mathrm{D}$ trajectory prediction of aircraft at the airport surface and have obtained a series of research results. In 2014, Ravizza et al. [3] and other researchers studied the path planning of aircraft at the airport surface considering time and fuel consumption and introduced a sequence diagram-based algorithm to solve the problem. In 2015, Weiszer et al. [4] proposed an aircraft at the airport surface motion database for the high calculation time requirements of existing speed configuration optimization methods and effectively separated path planning (routing and scheduling) and speed profile generation modules through precalculation to avoid the same repeated optimization of taxiway sections. In 2015, Weiszer et al. [5] used a 
multiobjective optimization method to solve the comprehensive optimization problem combining runway scheduling and ground motion problems. The proposed evolutionary algorithm is based on an improved congestion distance, taking into account delay costs and fuel prices. In 2016, $\mathrm{Li}$ and $\mathrm{Lu}$ [6] used support vector machines to perform position classification and trajectory determination of scene taxiing aircraft and applied data mining technology to predict scene aircraft taxiing time, determine scene taxiing hotspots, and determine conflict areas of the study. In 2016, Chen et al. [7] and others proposed the concept of active routing, combining $4 \mathrm{D}$ trajectory and routing scheduling into a multiobjective optimization problem and finally generating a more environment-friendly and cost-effective $4 \mathrm{D}$ trajectory. In 2017, Stewart et al. [8] considered that the routes and timetables generated by taxi time prediction may not be flexible, based on multiobjective fuzzy rules, and quantified the routes and time generated by taxi time prediction based on historical aircraft taxi data table uncertainty. In 2017, Wang et al. [9], based on the aircraft's taxiing motion model, discretized the taxiing speed and adopted a multitarget immune optimization method to study the specific relationship between taxiing speed and fuel consumption when an aircraft is launched using a fixed path relationship. In 2018, Zhang et al. [10] proposed an online velocity profile generation method, which simplified the nonlinear optimization model into three easy-to-handle composition problems and further optimized the feasible velocity curve to produce an improved high fuel efficiency velocity profile. In 2019, Zhu et al. [11] and others considered the aircraft taxi time and the number of large turns during taxiing to establish an aircraft at the airport surface taxi path optimization model with the shortest total taxi time as the goal. The genetic algorithm was used to solve the model.

It can be seen from the research situation at home and abroad that the taxi planning problem has achieved fruitful results in both theoretical research and practical application. However, most of the current studies assume that the aircraft is modeled based on the shortest taxi time under uniform taxi conditions, without considering the actual situation. Due to the turning section of the airport surface, the aircraft's speed profile changed, resulting in additional taxi time. Although precise algorithms such as multiobjective optimization take full consideration of various scene constraints, such algorithm models are complex and computationally intensive, and it is generally difficult to obtain the optimal solution in an acceptable time. Therefore, this article comprehensively considers the aircraft's taxiing distance and the number of turns during taxiing and plans the shortest path for the aircraft taxiing on the scene. Based on this, a multitarget speed profile model is established to weigh the time and fuel consumption during taxiing. Each path generates a more accurate speed profile that takes into account time and fuel efficiency, obtaining a scene aircraft taxiing $4 \mathrm{D}$ trajectory. The concept of maximum theoretical speed is added to the heuristic search process, which further simplifies the calculation amount. Compared with other complicated algorithms that consider multiple factors, the calculation speed is faster, from an environmental perspective, and considering the taxi time and thrust changes of the $4 \mathrm{D}$ trajectory and the comparison and calculation of the pollutant emissions when the ground aircraft adopts a multitarget speed profile, the accurate multitarget taxi $4 \mathrm{D}$ trajectory is more conducive to energy saving and emission reduction has a higher practical application value.

\section{Aircraft Taxi Shortest Path Planning}

2.1. Airport Surface Structure Modeling. The optimization object studied in this paper is the flight area where the aircraft runs on the ground, which mainly includes the runway, taxiway, and apron system in scene resources. On the roads of the airport surface, there are various types of intersections, and various types of intersections are composed of straight and curved roads interwoven to varying degrees. Therefore, the network structure of the airport surface is redefined to simplify the representation of the connection relationship in the scene network structure. Taking Xi'an Xianyang International Airport as an example, the simplified diagram of the simplified airport surface structure is as shown in Figure 1.

After simplifying the structure of the airport surface, the network connection relationship of the airport surface system can be clearly and intuitively understood. But it is not applicable to the design and solution processing of path planning algorithms. To this end, the scene structure is represented abstractly as $G=(V, E)$ in the form of an undirected graph, where $V$ represents the set of nodes in the taxiway system, which is composed of the intersections between taxiways, the intersections between taxiways and runways, parking spots, two ends of the runway, and so forth; $E$ represents the set of edges connecting various nodes in the taxiway system and is composed of taxiway sections between adjacent nodes in the taxiway system.

In this paper, the adjacency matrix is used to represent the connection relationship between nodes and the directed graph model is transformed into a matrix representation. Suppose that there are $m$ nodes in the airport surface structure diagram, which are represented by a matrix $C$ of $m * m$, and define the element $C_{i j}$ of the matrix:

$$
C_{i j}= \begin{cases}1, & \text { there is an edge from node } i \text { to node } j \\ 0, & \text { there is an edge from node } i \text { to node } j .\end{cases}
$$

In the path planning, the nodes of the scene road network and the taxiway sections must consider their attributes, and the attributes of the scene road network are defined according to the following requirements of $E-R$ relationship model:

(1) Road network (node number and path number)

(2) Path node (node number, $x$-coordinate, and $y$-coordinate); directional segment of the path (path number, start point, end point, distance, taxiway to which it belongs, wingspan restriction, running direction, and disable or fault) 


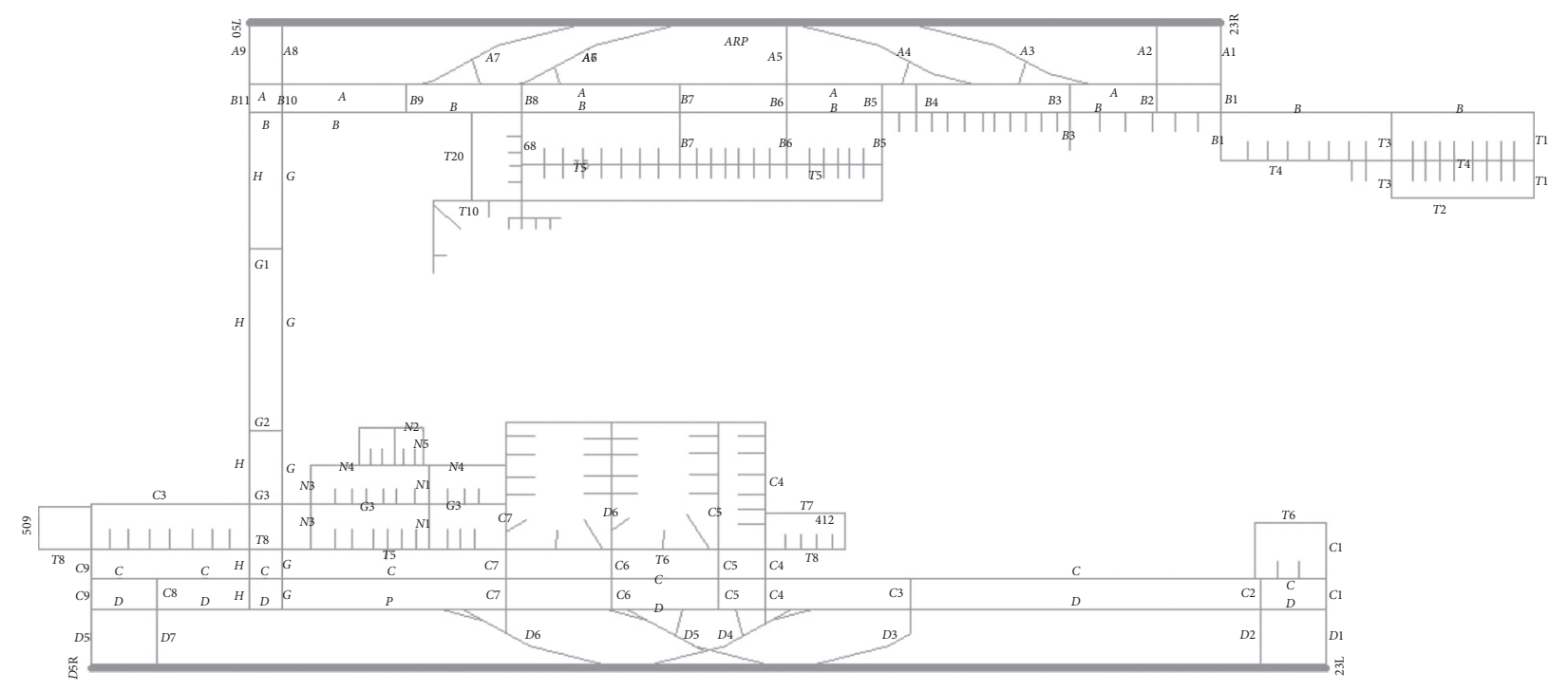

Figure 1: Xi'an Xianyang Airport structure simplified diagram.

When planning a route, the aircraft must consider its attributes. The attributes of the aircraft identification are as follows:

(1) Aircraft call sign

(2) Aircraft type

(3) Aircraft wingspan

(4) The current taxi speed of the aircraft

2.2. Aircraft Taxi Shortest Path Planning Model. For any aircraft $k$ in the aircraft set $F=\left\{f_{1}, f_{2}, \ldots, f_{n}\right\}$, the system generates $P$ preselected paths for it, and its $z$-th preselected taxi path $L_{k z}(1 \leq k \leq n, 1 \leq z \leq p)$ is composed of a set of ordered nodes $\left\{N_{1}, N_{2}, \ldots, N_{q}\right\}$. There are $M$ nodes in the airport network model. There are $q \leq M, N_{i}, N_{j}, N_{r} \in V$, $\left(N_{i}, N_{j}\right) \in \in E, i=1,2, \ldots, q, j=1,2, \ldots, q$. The variables used are as follows.

$x_{i j}=1$, indicating that aircraft $k$ passes through node $N_{i}$ of the taxiway and then taxies straight to node $N_{j}$; otherwise $x_{i j}=0 ; d_{i j}$ is the length of the straight taxiway road section $\left(N_{i}, N_{j}\right)$ in the taxiway system; $t_{i j}$ is the taxi time of the aircraft on the straight taxiway $\left(N_{i}, N_{j}\right) ; R_{r}=1$, indicating that the aircraft $k$ turns when passing through the taxiway node $N_{r}$; otherwise $R_{r}=0 ; d_{r}$ is the turning length of the aircraft $k$ at the node $N_{r}$ during taxiing of the scene; $t_{r}$ is the turning and taxiing time of the aircraft at the node $N_{r}$. Then the total taxi distance $D$ of the aircraft can be obtained by the following formula:

$$
D=\sum_{i=1}^{m} \sum_{j=1}^{m} x_{i j} d_{i j}+\sum_{i=1}^{m} R_{r} d_{r} .
$$

$\sum_{i=1}^{m} \sum_{j=1}^{m} x_{i j} d_{i j}$ is the taxi distance of the aircraft on each straight taxi section, where $x_{i j}$ is based on whether the edge $\left(N_{i}, N_{j}\right)$ is the taxiing path of aircraft $k$, and $x_{i j}$ takes the value of 1 or 0 . $\sum_{i=1}^{m} R_{r} d_{r}$ is the turning distance of the aircraft at each node that needs to turn, where $R_{i}$ is 1 or 0 according to whether the node $N_{r}$ is the turning point of aircraft $k . d_{r}$ can be expressed as

$$
d_{r}=\frac{\theta_{r} \pi r}{180^{\circ}}
$$

According to [11], the cosine theorem is used to solve the aircraft steering angle. The taxiing process of the aircraft during the turn is as follows.

As shown in Figure 2, because the scene topology diagram is simplified, the scene aircraft $k$ initially taxies at node $N_{u}$ and then continuously taxies through the two nodes $N_{g}$ and $N_{w}$. In reality, the aircraft has a turn length at point $N_{g}$, and the aircraft started to taxi at point $N_{u}$ and started to turn from point $N_{r}$. After the turn at point $N_{f}$, it continued to taxi to $N_{w}$. Then the taxi distance of this road section is actually the sum of the straight line length $d_{u r}$, the turning length $d_{r}$, and the straight line length $d_{f w}$.

2.3. Solving Path Planning Models. The aircraft path taxiing path planning model established in this paper has many variables, some equations are nonlinear, and traditional algorithms are difficult to solve, such as integer programming. In order to solve this problem, the Bellman-Ford algorithm and the $\mathrm{A}^{*}$ algorithm are combined to solve the model. The model solving algorithm designed in the paper is as follows.

In this paper, the goal is to find the path with the shortest taxiing distance of $\mathrm{P}$ aircrafts; let $g(n)$ be the taxiing distance from the start of the path to the current node $n$, and $h(n)$ represents the shortest slip distance from the current node to the target node. Then $f(n)$ represents the total slip distance of the aircraft from the start node of the path to the target node. Among them, $h(n)$ is executed before the algorithm is executed and preprocessed: all road sections of the airport 


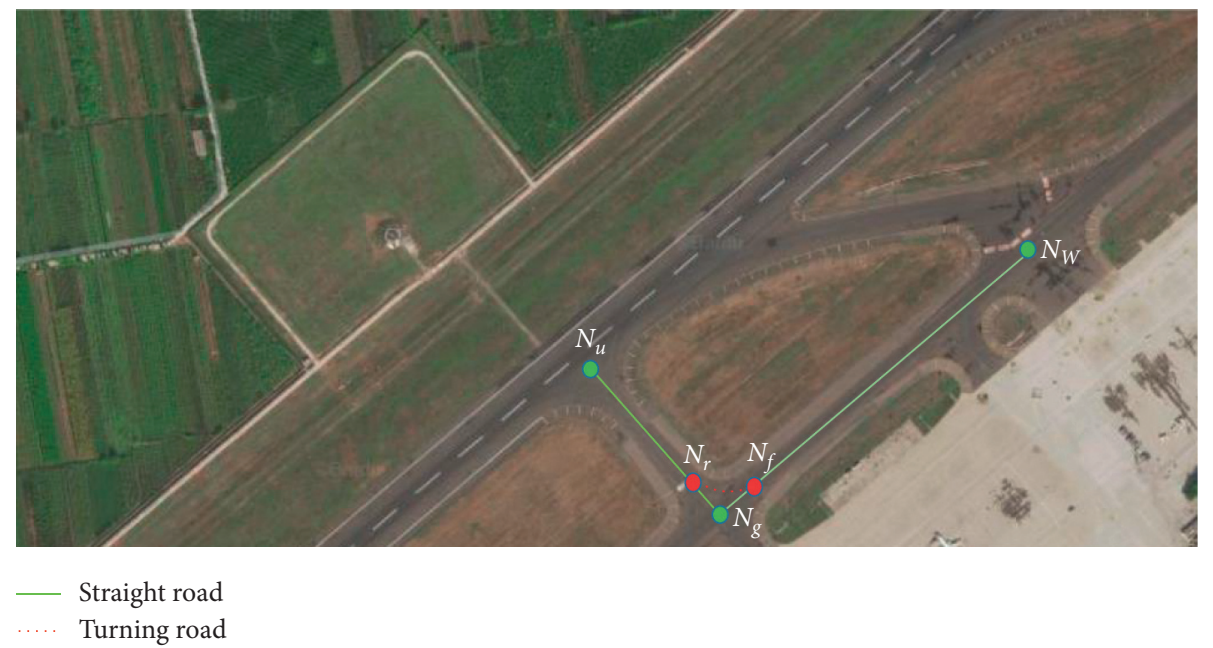

Figure 2: Aircraft turning section taxiing process.

are reversed, and the Bellman-Ford algorithm is executed from the punctuation point as the starting point to find the shortest taxi distance from the target point to all points. The value is $H(n)$ value at this point.

\section{Modeling Taxi Time Profile considering Time and Fuel}

Based on the $\mathrm{P}$ taxi paths obtained from the shortest path planning, the purpose of multiobjective speed profile modeling is to generate a set of unobstructed speed curves that satisfy the optimal time and fuel for each path, called the Pareto solution set $Y_{i}$. Therefore, the $4 \mathrm{D}$ trajectory of the aircraft at the airport surface taxiing is obtained, as shown in Figure 3.

\subsection{Aircraft Taxi Time Modeling}

3.1.1. Discretization of Aircraft Taxi Trajectory. During the taxiing of an aircraft, its taxiing speed is continuously changing. In order to reduce the computational complexity and calculation time of the algorithm, it is necessary to discretize the taxi speed and taxi trajectory.

During the aircraft's taxiing process, the speed curve on each link $\left(N_{i}, N_{j}\right)$ can be subdivided into 4 parts, as shown in Figure 4. The length of each part represents the taxiing distance of the aircraft in different operating phases, and the taxiing speed of the aircraft also changes according to the operating status.

In the first stage, the aircraft performs uniform acceleration motion, the acceleration $a_{1}$ is a constant value, and the taxi speed is accelerated from $v_{0}$ to $v_{1}$. The value of $v_{1}$ depends on the length $d_{1}$ of the first stage.

The aircraft maintains a speed $v_{1}$, the duration of which depends on the length $d_{2}$ of the second phase.

In the third and fourth stages, the aircraft performs deceleration. The difference between these two stages is that the fourth stage needs to be decelerated from $v_{3}$ (the final speed of the third stage of the aircraft) to $v_{4}$ in the shortest time at the maximum deceleration rate $a_{4}=a_{\max }$. The length of the third stage is $d_{3}=d-d_{1}-d_{2}-d_{4}$, and $v_{3}$ can be determined by $a_{4}, v_{4}$, and $d_{4}$.

Therefore, there are 4 variables $a_{1}, d_{1}, d_{2}, d_{4}$ for each link $\left(N_{i}, N_{j}\right)$. By calculating the values of four variables, the speed curve and objective function value of the link can be obtained.

3.1.2. Taxi Time Model. For each link $\left(N_{i}, N_{j}\right)$, the speed curve of the link can be determined through 4 decision variables $a_{1}, d_{1}, d_{2}$, and $d_{4}$ and the time for taxiing with the speed curve can be determined as follows:

$$
\mathrm{TT}_{i j}=\sum_{s=1}^{4} t_{s} .
$$

In the formula, we have the following:

$T T_{i j}$ is the taxi time used by the aircraft on the link $t_{s}$ is the time consumption of each stage of the speed curve, and $s=1,2,3,4$

For the complete taxi path $L_{k z}$ of aircraft $k$, which is composed of multiple links, the objective function $g_{1}$ of taxi time can be further expressed as

$$
g_{1}=\sum_{\left(N_{i}, N_{j}\right) \in L_{k z}} \mathrm{TT}_{i j} \text {. }
$$

3.2. Aircraft Taxiing Fuel Consumption Modeling. The discrete aircraft speed profile includes four phases: acceleration, constant speed, braking, and emergency braking. The thrust level of the aircraft in the acceleration and constant speed segments is obtained according to [8], assuming that the thrust level in the braking and emergency braking phases $\varepsilon=5 \%$, and the turning phase $\varepsilon=7 \%$. According to the fuel flow rate in the ICAO emission database and linear interpolation, the fuel flow rate $f_{s}$ corresponding to the thrust level at each stage in the speed profile is obtained by linear 


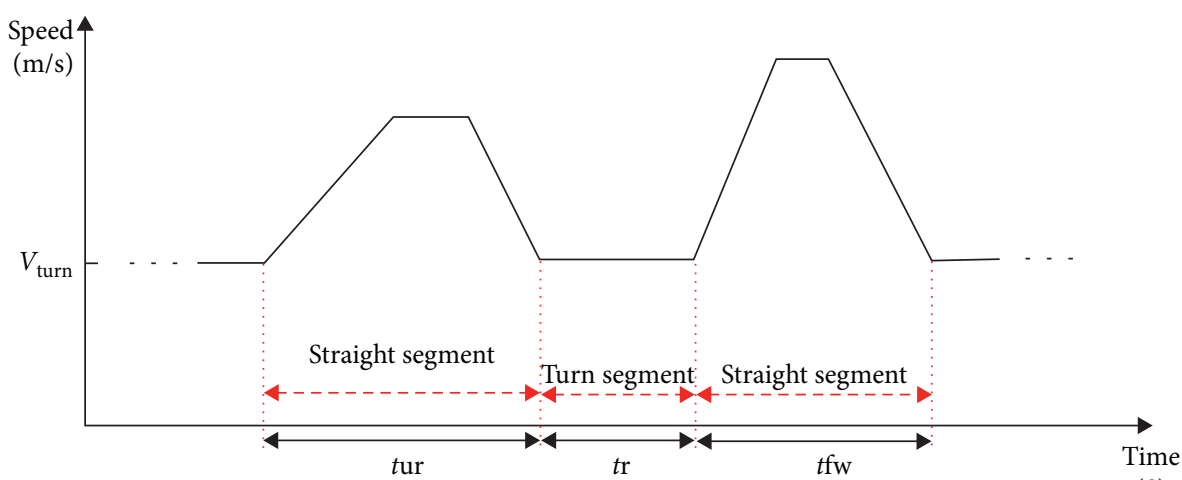

Figure 3: Partial multitarget taxiing profile.

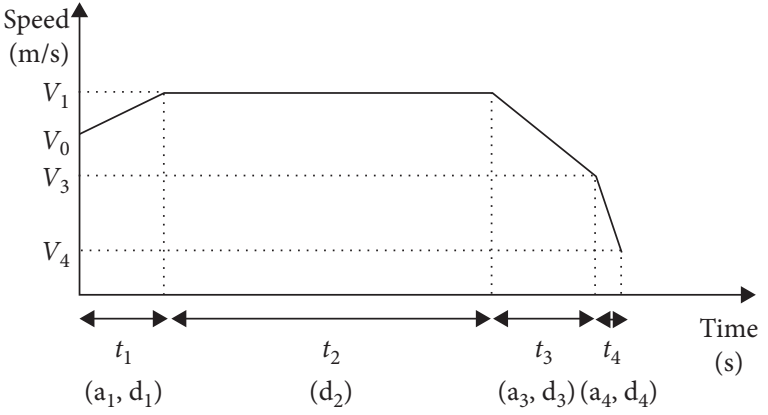

FIgURE 4: A speed profile with four phases.

interpolation. Then, for each link $\left(N_{i}, N_{j}\right)$, the fuel consumption of taxiing at this speed curve can be determined as follows:

$$
\mathrm{FF}_{i j}=\sum_{s=1}^{4} f_{s} \cdot t_{s}
$$

In the formula, we have the following:

$f_{s}$ is the fuel flow rate at each stage of the speed curve, and $s=1,2,3,4$

$t_{s}$ is the time consumption of each stage of the speed curve, and $s=1,2,3,4$

For the complete taxiing path $L_{k z}$ of aircraft $k$, which is composed of multiple links, the objective function of taxiing fuel consumption $g_{2}$ can be further expressed as

$$
g_{2}=\sum_{\left(N_{i}, N_{j}\right) \in L_{k z}} \mathrm{FF}_{i j} .
$$

3.3. Restrictions. For each link $\left(N_{i}, N_{j}\right)$, the taxi speed profile of aircraft $k$ is mainly determined by four decision variables $a_{1}, d_{1}, d_{2}, d_{4}$. Decision variables are calculated sequentially, and, once determined, they will be used to further calculate the next decision variable. Due to the need to integrate the best speed curve generation method into the routing and scheduling module to provide online decision making, many decision variables may result in failure to meet time requirements. In view of this, the following assumptions are made on the problem of multitarget velocity profile generation:

(1) The aircraft accelerates with the maximum acceleration $a_{\max }$ to minimize the acceleration time.

(2) Based on the ICAO emission database method, the fuel consumption during braking is equivalent to the fuel combustion during constant speed. Because braking does not save fuel, the aircraft's constant speed travel distance $d_{2}$ is maximized. Using the maximum deceleration, the driving distance $d_{4}$ during the rapid braking phase when decelerating from $v_{1}$ to $v_{4}$ can be expressed by the following formula:

$$
d_{4}=\frac{v_{1}^{2}-v_{4}^{2}}{2 a_{\max }}
$$

Based on this assumption, the only undecided decision variable is the acceleration distance $d_{1}$, and heuristic search method is used to search for the best value of $v_{1}$ within the allowable range to determine $d_{1}$.

Before searching for $v_{1}$, the maximum theoretical speed $v_{\text {theory }}$ is added, and its value is determined by the length $d_{i j}$ of the link $\left(N_{i}, N_{j}\right)$; the formula is as follows:

$$
\begin{aligned}
& v_{\text {theory }}^{2}-v_{0}^{2}=2 a_{1} d_{1}, \\
& v_{\text {theory }}^{2}-v_{t}^{2}=2 a\left(d_{i j}-d_{1}\right)_{\max } .
\end{aligned}
$$

In the formula, we have the following:

$d_{i j}$ is the length of the link $\left(N_{i}, N_{j}\right)$

$d_{1}$ is the acceleration distance of the aircraft in the first stage

$v_{\text {theory }}$ is the maximum theoretical speed

$v_{0}$ is the initial speed on the link $\left(N_{i}, N_{j}\right)$

$v_{t}$ is the final speed on the link $\left(N_{i}, N_{j}\right)$

There are two situations:

(1) $v_{\text {theory }} \geq v_{\text {max }}$. 
At this time, it is shown that the link is long enough, and the aircraft satisfies the acceleration of $a_{1}$ to $v_{\max }$ and then decelerates to the final speed $v_{t}$ of the link $\left(N_{i}, N_{j}\right)$. Search for the best value of $v_{1}$ within $v_{\max }$.

(2) $v_{\text {theory }}<v_{\max }$.

At this point, it is shown that the link length is not enough to accelerate to $v_{\max }$. The aircraft will accelerate to $v_{\text {theory }}$ by $a_{1}$ and then decelerate by $a_{\max }$ to meet the situation where the link end reaches $v_{t}$. Search for the best value of $v_{1}$ within $v_{\text {theory }}$.

3.4. Multiobjective Velocity Profile Model Solution. This paper uses a heuristic search method to search the decision variable $v_{1}$, weighs the taxi time and fuel consumption, and finally generates a multitarget speed profile for the selected path. The specific search steps are as follows:

(1) Input the segmented path $L_{k z}$

(2) Traverse weights $u_{1}$ and $u_{2}$ :

$u_{1}$ from 0 to 1 in steps of $1 / 12$

$$
u_{2}=1-u_{1} \text {. }
$$

(3) Corresponding to the determined weight, take the chain $\left(N_{i}, N_{j}\right)$ on the path $L_{k z}$ :

(1) Linear link

Speed value $v_{1}=\left[v_{\min }, v_{\max }, 1\right]$, a total of 12 schemes

Introduce $v_{\text {theory }}$ to traverse the speed value during the acceleration phase

Corresponding to the determined speed $v_{1}$, find

the taxi time $\mathrm{TT}_{i j}$ and fuel consumption $\mathrm{FF}_{i j}$ of the link $\left(N_{i}, N_{j}\right)$

Solve $u_{1} * T T_{i j}+u_{2} * F F_{i j}$

Select the corresponding $v_{1}$ when the benefit is the smallest, and use this value to determine the speed profile of the link $\left(N_{i}, N_{j}\right)$

(2) Turn link

Calculate the cornering speed of $5.14 \mathrm{~m} / \mathrm{s}$, and find the cornering benefit value

(4) Summing the fuel consumption $\mathrm{FF}_{i j}$ and time $\mathrm{TT}_{i j}$ of all links $\left(N_{i}, N_{j}\right)$ to obtain the objective function values $g_{1}$ and $g_{2}$ :

Speed profile generation of taxi path

Output $g_{1}$ and $g_{2}$

\section{Estimation of Pollutant Emissions during Taxiing}

Through the emission coefficients of different types of engines, the pollutant emissions during the landing and takeoff (LTO) cycle of the flight can be calculated. This article mainly analyzes the pollutant emissions during the taxi phase. The main influencing factors include (1) aircraft model and the corresponding number of engines; (2) engine model where different engine fuel combustion efficiency and corresponding pollutants are different; (3) types of pollutants discharged and corresponding emission coefficients; (4) engine thrust values where different thrusts correspond to different fuel flow rates and pollutant emissions; and (5) taxi time. According to the LTO cycle defined by ICAO, the operating mode and emissions of the Airbus A320 engine with two CFM56-5-A1 engines are shown in Table 1.

It can be seen from Table 1 that the amount of pollutant emissions during the taxi phase is much larger than that in other phases, which deserves special attention. Because the LTO cycle defined by ICAO calculates taxi emissions according to a fixed taxi thrust and, in reality, due to the different taxi actions of the aircraft, the engine thrust is not always maintained at $7 \%$, so the pollutants in the aircraft ground taxi phase are calculated by this calculation model. The amount of emissions is quite different from the actual situation, so this paper considers the actual taxiing speed and corresponding thrust of the aircraft during the ground taxi phase and obtains the actual taxi speed based on the fuel flow rate and pollutant emission coefficient values corresponding to different taxi thrust values. The amount of pollutant emissions has further improved the accuracy of emissions calculations. The total amount of taxiing emissions from surface aircraft $E$ can be expressed as

$$
\begin{aligned}
E & =\sum_{f_{n}} E_{f_{n}} \\
E_{f_{n}} & =\sum_{\left(N_{i}, N_{j}\right)} \sum_{w} E_{i j, w} t_{s} \times f_{s} \times \mathrm{EI}_{s, w}, \\
E_{i j, w} & =\sum_{s=1}^{4}
\end{aligned}
$$

where $t_{s}$ indicates the taxi time of the aircraft in the speed profile phase $s, f_{s}$ indicates the aircraft's fuel consumption coefficient in the speed profile phase $s, \mathrm{EI}_{s, w}$ indicates the aircraft's emission coefficient of the pollutant $w$ discharged in the speed profile phase $s, \mathrm{E}_{i j, w}$ and indicates the aircraft is in the link. The amount of pollutant $w$ discharged during taxiing $E_{f_{n}}$ represents the total amount of pollutant discharged when the aircraft $f_{n}$ taxis.

\section{Example Analysis}

\subsection{Aircraft Taxi Shortest Path Generation}

5.1.1. Experimental Settings. This article takes the ground taxi system of Xi'an Xianyang Airport as an example and uses the $\mathrm{A}^{*}$ algorithm to optimize the model. Xi'an Xianyang Airport has 3 terminals and two parallel runways. The flight data of Xi'an Xianyang Airport on May 2nd, 2019, from 15:16:00 to $15: 28: 20$ was used for simulation calculation. The taxi schedule of the flight is shown in Table 2. Plan 3 preselected taxi paths for each aircraft according to their respective flight plans; that is, the number of preselected paths $p=3$.

5.1.2. Simulation Results. The system gives the feasible taxi path of each aircraft and the taxi path length and number of turns of taxiing from the starting node to the target node 
TABLE 1: Standard LTO cycle working mode and benchmark emission index.

\begin{tabular}{lcccccc}
\hline Condition & Thrust $(\%)$ & Time $(\mathrm{min})$ & Fuel consumption $(\mathrm{kg} / \mathrm{sec})$ & $E I_{\mathrm{HC}}(\mathrm{g} / \mathrm{kg})$ & $E I_{\mathrm{CO}}(\mathrm{g} / \mathrm{kg})$ & $E I_{\mathrm{NO}}(\mathrm{g} / \mathrm{kg})$ \\
\hline Take-off & 100 & 0.7 & 3.2 & 0 & 0.2 & 34.38 \\
Climb & 85 & 2.2 & 1.58 & 0.01 & 0.46 & 26.44 \\
Approach & 30 & 4.0 & 0.85 & 1.46 & 10.89 \\
Taxi & 7 & 26 & 0.28 & & 17.94 & 4.71 \\
\hline
\end{tabular}

TABle 2: Flight taxi schedule.

\begin{tabular}{lccc}
\hline Flight number & Arrival/departure & Start point & End point \\
\hline NS8264 & Arrival & 06 & 165 \\
HU7577 & Departure & 166 & 137 \\
MU4405 & Arrival & 154 & 167 \\
MU5569 & Departure & 168 & 1 \\
HU7817 & Departure & 169 & 1 \\
MU2158 & Arrival & 7 & 170 \\
\hline
\end{tabular}

TABLe 3: Preselected path and time for aircraft NS8264.

\begin{tabular}{lccc}
\hline Flight number & Preselected path & Taxi distance $(\mathrm{m})$ & Turning distance $(\mathrm{m})$ \\
\hline NS8264 & $6->12->16->33->32->31->47$ & 2853.14473 & 1490.01908 \\
NS8264 & $7->60->165$ & 2853.14473 & 1490.01908 \\
NS8264 & $6->12->16->33->32->48->61->60->165$ & 3130.12683 & 1490.01908 \\
\hline
\end{tabular}
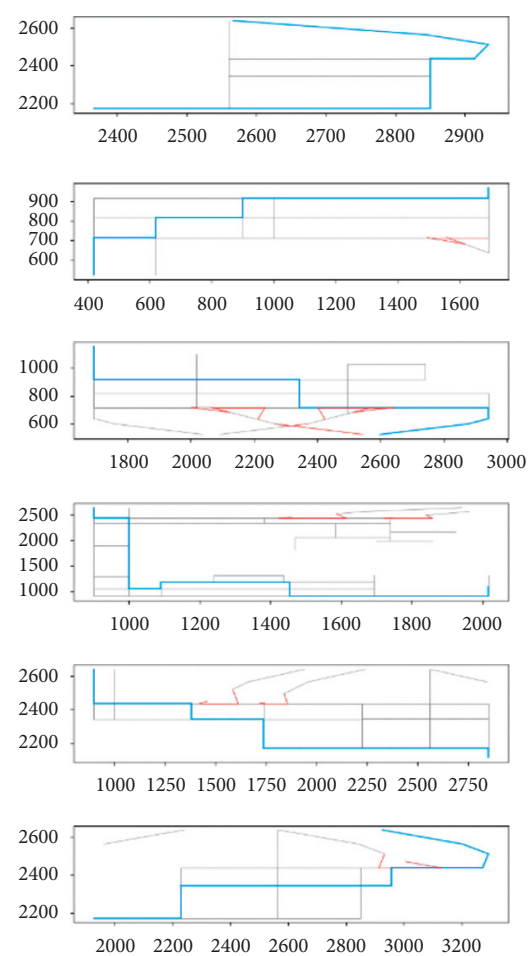
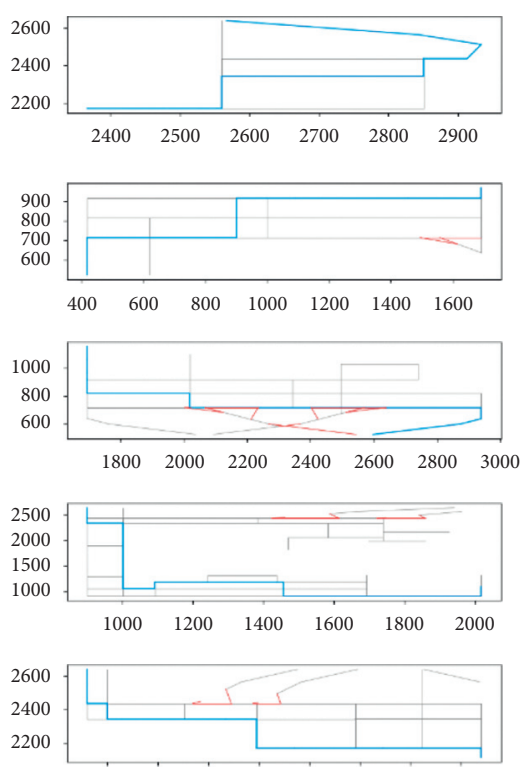

$1000 \quad 1250150017502000225025002750$

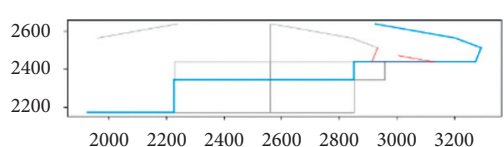

(a)
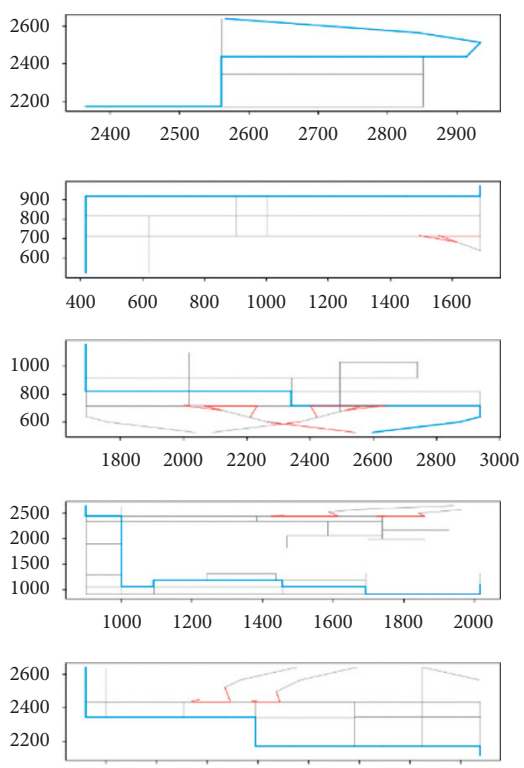

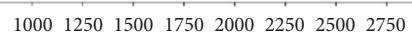

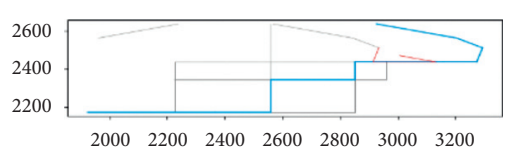

Figure 5: Continued. 

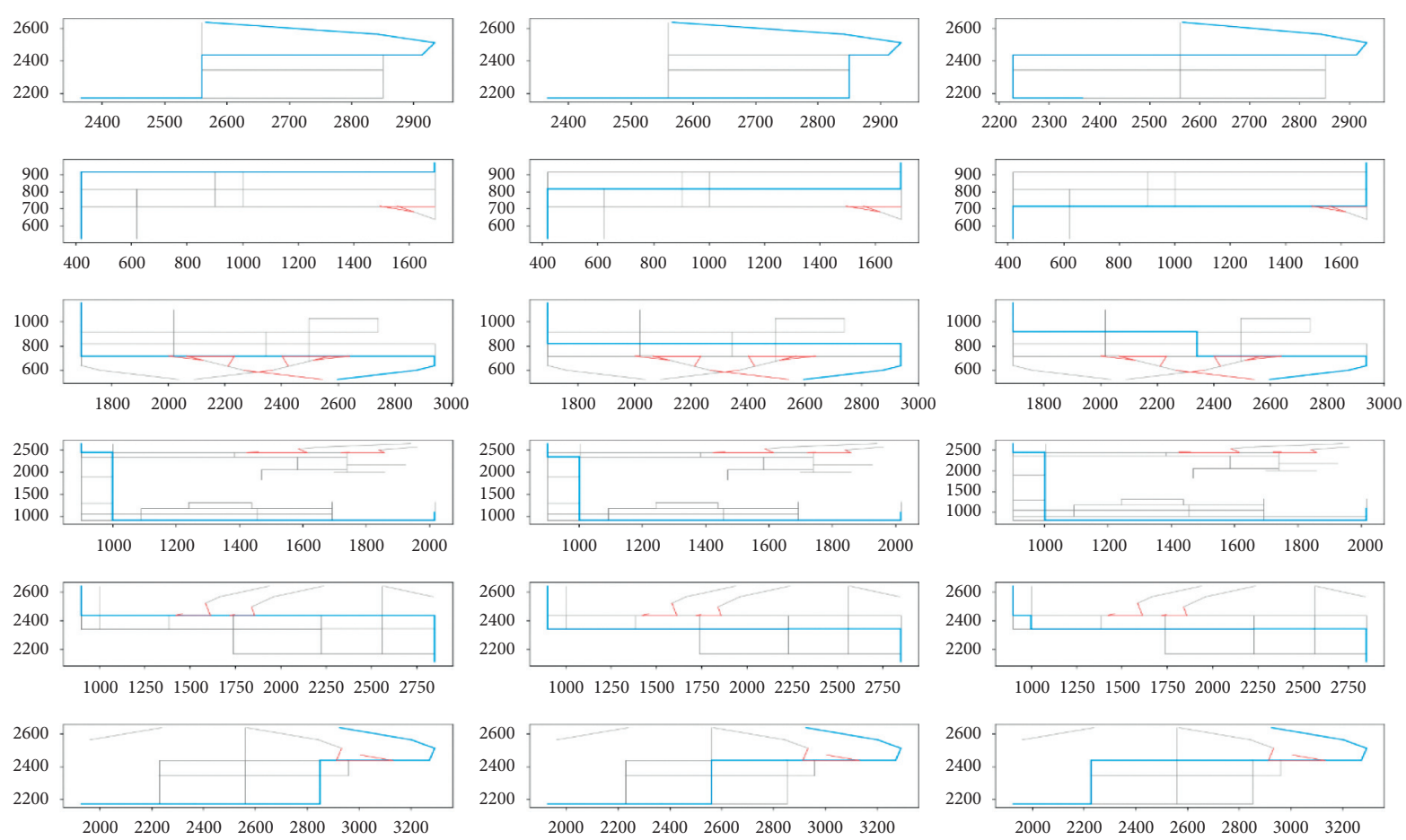

(b)

FIgURE 5: The aircraft considers the comparison of the taxiing path before and after the turn. (a) The comparison of the taxiing path before considering the turn. (b) The comparison of the taxiing path after considering the turn.

according to this path. The preselected path and time for aircraft NS8264 are shown in Table 3.

As can be seen from Table 3, the taxi path planning system considers the number of turns and provides three different preselected paths for each aircraft, which are sorted in increasing order according to the total taxi distance. For a nonsteering node on the aircraft's taxi path, the aircraft is considered to taxi directly into the node and only takes up the node at a certain moment; for a turning node on the aircraft's taxi path, it is considered that the aircraft takes a certain amount of time to perform a turning operation after taxiing into the node, and then the aircraft taxies out of the node.

Figure 5 shows the taxi path without considering the turn and the turning distance of the aircraft path. The red section indicates the section that cannot be driven due to direction restrictions. It can be seen from the figure that the route considering the turning distance reduces the aircraft's taxi nodes and the number of turns.

The taxi data of the six aircraft paths listed in Table 3 before and after considering the taxi turn distance are calculated. The comparison results are shown in Table 4.

Comparing the statistical data in Table 4, it can be seen that the total taxi distance and turning distance of the aircraft are reduced after the path optimization, and the taxi turn distance is the main factor for the reduction of the total taxi distance.

\subsection{Multitarget Velocity Profile Generation}

5.2.1. Experimental Settings. According to ICAO standards, the aircraft's linear speed does not exceed 30 knots, and the turn taxi speed does not exceed 10 knots. It is assumed that the minimum taxi speed $v_{\min }$ of the aircraft is $5.14 \mathrm{~m} / \mathrm{s}$ and the maximum speed $v_{\max }$ is $15.43 \mathrm{~m} / \mathrm{s}$. The speed of the aircraft is constant when turning. The turning speed is set to $5.14 \mathrm{~m} / \mathrm{s}$. In order to ensure passenger comfort, the maximum acceleration and deceleration rate $a_{\max }$ is set to $0.98 \mathrm{~m} \cdot \mathrm{s}^{-2}$.

Based on the obtained shortest taxi path for taxiing, the taxi path is divided into straight sections and turning sections, and the initial speed, final speed, and section length information of each section are obtained, as shown in Table 5.

Take flight number NS8264 as an example. The flight is an approaching aircraft. The initial speed is $5.14 \mathrm{~m} / \mathrm{s}$ and the taxiing speed is $5.14 \mathrm{~m} / \mathrm{s}$ on the path segment " $6-12$ " to the turning node "12." At a speed of $5.14 \mathrm{~m} / \mathrm{s}$, the taxi is at a constant speed at the turning point " 12 ," and then taxies on the path segment " $12-16$ " at a speed of $5.14 \mathrm{~m} / \mathrm{s}$ to reach the next turning point " 16 " at a speed of $5.14 \mathrm{~m} / \mathrm{s}$. The speed of $5.14 \mathrm{~m} / \mathrm{s}$ taxies on the turning taxiway at a constant speed, and so on, until all the paths are completed, and the speed is finally reduced to 0 when it reaches the apron. 
TABle 4: Comparison of important data of aircraft before and after turning.

\begin{tabular}{ccccc}
\hline & \multicolumn{2}{c}{ Steering distance $(\mathrm{m})$} & \multicolumn{2}{c}{ Taxi distance (m) } \\
& No turning & Turning & No turning & Turning \\
\hline \multirow{3}{*}{ MU5569 } & 2899.458 & 1179.943 & 5836.950 & 4201.185 \\
& 2988.399 & 1268.883 & 5925.891 & 4290.125 \\
\hline
\end{tabular}

TABLE 5: NS8264 taxi path segmentation information table.

\begin{tabular}{|c|c|c|c|c|c|}
\hline Number & Path segment & Segment type & Start speed $(\mathrm{m} / \mathrm{s})$ & End speed $(\mathrm{m} / \mathrm{s})$ & Length $(\mathrm{m})$ \\
\hline 1 & $6-12$ & Straight & 5.14 & 5.14 & 286.846 \\
\hline 2 & 12 & Turn & 5.14 & 5.14 & 55.799 \\
\hline 3 & $12-16$ & Straight & 5.14 & 5.14 & 103.767 \\
\hline 4 & 16 & Turn & 5.14 & 5.14 & 282.070 \\
\hline 5 & $16-33$ & Straight & 5.14 & 5.14 & 77.663 \\
\hline 6 & 33 & Turn & 5.14 & 5.14 & 227.168 \\
\hline 7 & $33-31$ & Straight & 5.14 & 5.14 & 353.152 \\
\hline 8 & 31 & Turn & 5.14 & 5.14 & 403.196 \\
\hline 9 & $31-60$ & Straight & 5.14 & 5.14 & 264.199 \\
\hline 10 & 60 & Turn & 5.14 & 5.14 & 521.783 \\
\hline 11 & $60-165$ & Straight & 5.14 & 0 & 194.420 \\
\hline
\end{tabular}

5.2.2. Simulation Results. The system generated the speed profile of each aircraft on the shortest preselected path, as shown in Figure 6 (the abscissa of the speed profile is the taxi time and the ordinate is the taxi speed; the abscissa of the thrust curve is the taxi time, and the ordinate is the thrust value).

It can be seen from Figure 6 that when searching with different weights, the aircraft generates completely different speed profiles, which depends on the decision of the controller in practical applications. Taking the shortest path of flight NS8264 as an example, the taxi data of the speed profile at different weights are counted. The comparison results are shown in Table 6.

Comparing the statistical data in Table 5, it can be seen that when the time weight is the largest, the total taxi time of the speed profile generated is the least, but the fuel consumption is the largest; otherwise, when the fuel weight is the largest, the total taxi time in the speed profile is the longest, but the fuel consumption is the smallest. When the aircraft is taxiing at different speeds and accelerations on a specified path, the effect on taxi time cost and taxi fuel consumption cost is different. The pursuit of the optimal time cost will inevitably cause excessive fuel consumption, and the taxi time when the fuel consumption is optimal is not really optimal from the perspective of the total taxi cost. Taking the shortest path of flight NS8264 as an example, the Pareto front of the best speed profile is shown in Figure 7.

It can be clearly seen from the experimental results that the optimal taxiing time for the aircraft to complete the designated path does not correspond to the optimal taxiing fuel consumption, and the two are not in direct relationship. Decreasing the taxi time of the aircraft does not mean that the fuel consumption is reduced. On the contrary, reducing the taxi time of the aircraft will change the taxi speed, and frequent acceleration and deceleration will bring more fuel consumption.

This paper compares the time of the system running algorithm before and after the improvement, as shown in Table 7.

Under the premise of ensuring the generation of accurate $4 \mathrm{D}$ taxiing trajectories, the algorithm in this paper significantly shortens the running time of the algorithm and satisfies the application in the actual dynamic environment (ICAO, 2004). The path planning algorithm in this paper is more effective than before.

5.3. Calculation of Taxiing Pollutant Emission. 6Check the fuel consumption rate and pollutant emission coefficient of the aircraft through the ICAO engine emission database (as shown in Table 8). Use the above multitarget speed profile model to obtain the thrust values of each stage of the aircraft surface taxi, according to the engine installed in each aircraft Type and linear interpolation to obtain the fuel consumption rate and pollutant emission coefficients corresponding to different thrust values and to obtain the pollutant emissions when each aircraft adopts a multitarget speed profile. The three glide speed profiles of NS8264 and their pollutant emissions are shown in Table 9.

In order to verify the rationality and effectiveness of the method in this paper, the flight volume data of Xi'an Xianyang Airport in the first half of 2019 is counted, and the pollutant emissions are solved based on the accurate multitarget taxi speed profile, and the average total pollutant emissions for flights in the first half of the year are obtained. The calculated results are compared with the actual total emissions, as shown in Table 10. 

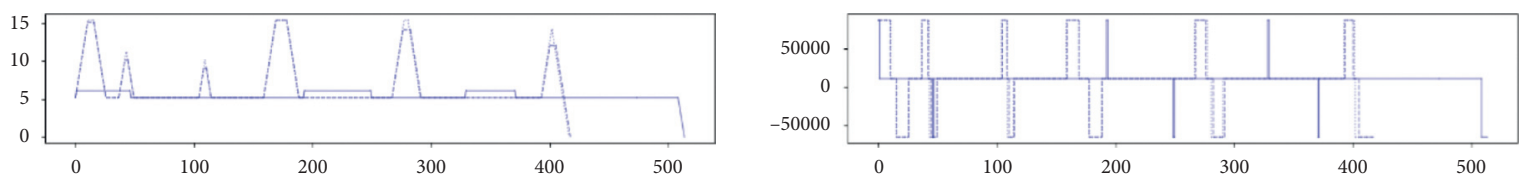

$u 1=6 / 12, u 2=12 / 12$

$u 1=6 / 12, u 2=6 / 12$

$u 1=11 / 12, u 2=1 / 12$

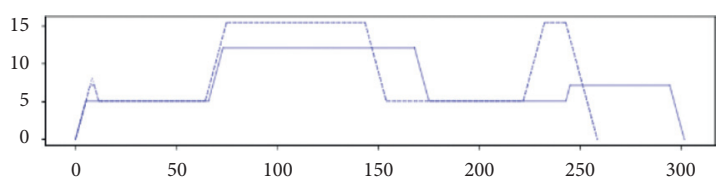

$u 1=6 / 12, u 2=12 / 12$

$u 1=6 / 12, u 2=6 / 12$

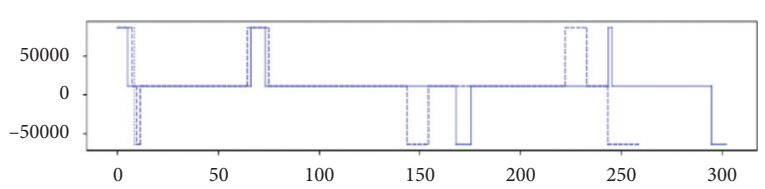

$u 1=6 / 12, u 2=12 / 12$

$u 1=6 / 12, u 2=6 / 12$

$u 1=11 / 12, u 2=1 / 12$

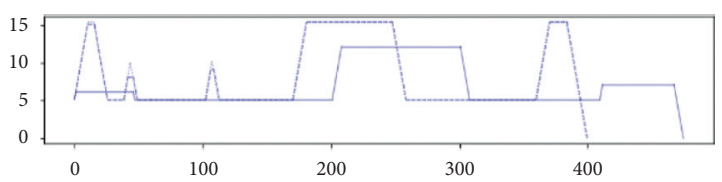

$u 1=6 / 12, u 2=12 / 12$

$u 1=6 / 12, u 2=6 / 12$

$u 1=11 / 12, u 2=1 / 12$

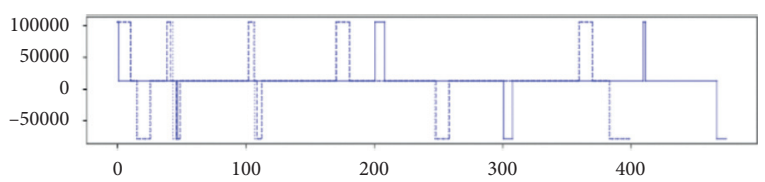

$u 1=6 / 12, u 2=12 / 12$

$\begin{aligned} u 1 & =6 / 12, u 2=12 / 12 \\ u 1 & =6 / 12, u 2=6 / 12\end{aligned}$

$u 1=11 / 12, u 2=1 / 12$

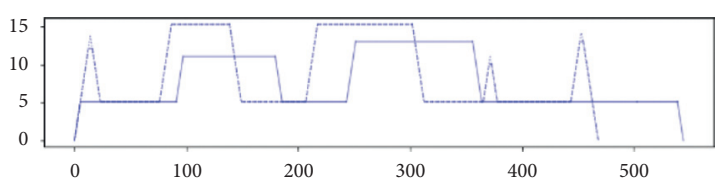

$\mathrm{ul}=6 / 12, u 2=12 / 12$

$\mathrm{ul}=6 / 12, u 2=6 / 12$

$\mathrm{ul}=11 / 12, u 2=1 / 12$

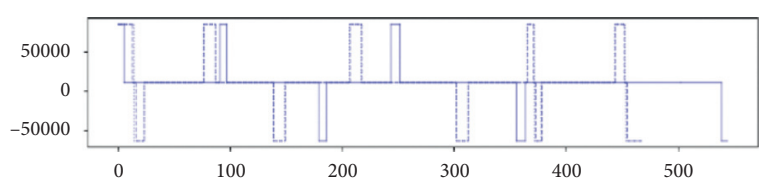

$u 1=6 / 12, u 2=12 / 12$

$u 1=6 / 12, u 2=6 / 12$

$u 1=11 / 12, u 2=1 / 12$

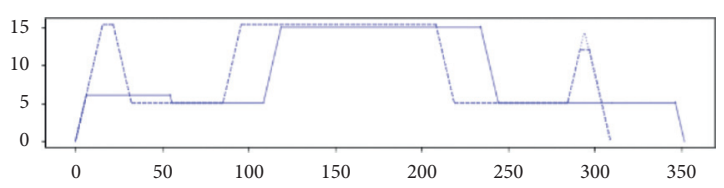

$\begin{aligned} u 1 & =6 / 12, u 2=12 / 12 \\ u 1 & =6 / 12, u 2=6 / 12\end{aligned}$

$u 1=11 / 12, u 2=1 / 12$

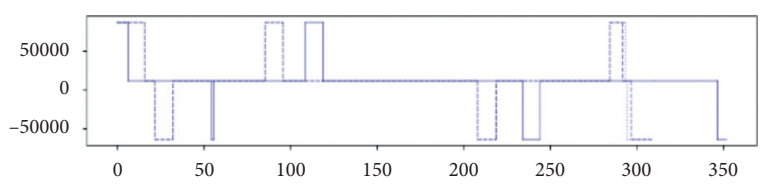

$u 1=6 / 12, u 2=12 / 12$

$u 1=6 / 12, u 2=6 / 12$

$u 1=11 / 12, u 2=1 / 12$

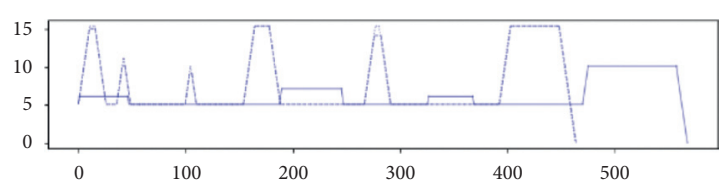

$u 1=6 / 12, u 2=12 / 12$

$u 1=6 / 12, u 2=6 / 12$

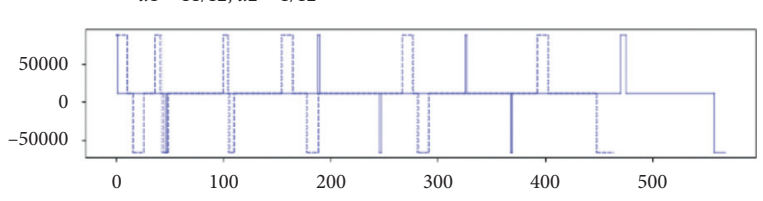

$u 1=6 / 12, u 2=12 / 12$

$u 1=6 / 12, u 2=6 / 12$

$u 1=6 / 12, u 2=12 / 12$

$u 1=6 / 12, u 2=6 / 12$

$u 1=11 / 12, u 2=1 / 12$

Figure 6: The best speed profile with the largest fuel consumption, the same fuel consumption and time weight, and the highest time weight.

TABLE 6: Comparison of NS8264 shortest path taxiing speed profile data.

\begin{tabular}{|c|c|c|c|}
\hline Time weight $u_{1}$ & Fuel weight $u_{2}$ & Total taxi time (s) & Total fuel consumption $(\mathrm{kg})$ \\
\hline $0 / 12$ & $12 / 12$ & 513.3944 & 45.5902 \\
\hline $1 / 12$ & $11 / 12$ & 454.4269 & 47.6240 \\
\hline $2 / 12$ & $10 / 12$ & 433.9038 & 50.3658 \\
\hline $3 / 12$ & $9 / 12$ & 425.2658 & 52.5567 \\
\hline $4 / 12$ & $8 / 12$ & 420.4226 & 54.5559 \\
\hline $5 / 12$ & $7 / 12$ & 418.5146 & 55.6877 \\
\hline $6 / 12$ & $6 / 12$ & 417.2933 & 56.7442 \\
\hline $7 / 12$ & $5 / 12$ & 416.5771 & 57.5609 \\
\hline $8 / 12$ & $4 / 12$ & 416.5116 & 57.6655 \\
\hline $9 / 12$ & $3 / 12$ & 416.3747 & 58.0305 \\
\hline $10 / 12$ & $2 / 12$ & 416.1677 & 58.7583 \\
\hline $11 / 12$ & $1 / 12$ & 416.1677 & 58.7583 \\
\hline
\end{tabular}




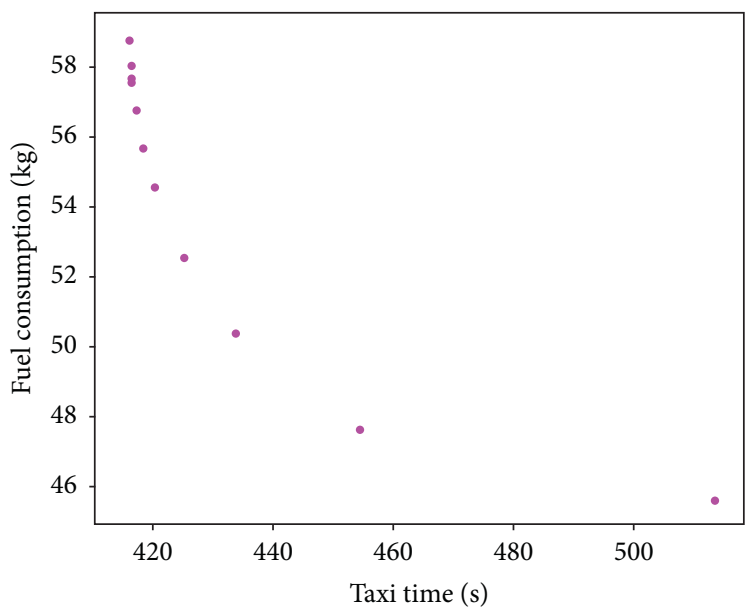

Figure 7: Pareto frontier of the best speed profile for flight NS8264.

TABLE 7: Comparison of running time of simulation results.

\begin{tabular}{lcccc}
\hline & Operation hours (s) & Time reduction rate compared to A* (\%) & Time reduction rate compared to the original search (\%) \\
\hline $\mathrm{A}^{*}$ & 2.13 & - & - \\
Improved $\mathrm{A}^{*}$ & 0.97 & 54.5 & - \\
Original search & 1.96 & - & - \\
Heuristic search & 0.83 & - & 59.1 \\
\hline
\end{tabular}

TABLe 8: The fuel consumption rate and pollutant emission coefficient corresponding to the $7 \%$ thrust value of the aircraft.

\begin{tabular}{lcccccc}
\hline Flight $(\mathrm{kg} / \mathrm{sec})$ & Type & Engine & Fuel flow rate & Hydrocarbon $(\mathrm{kg} / \mathrm{sec})$ & Oxycarbide $(\mathrm{kg} / \mathrm{sec})$ & Oxynitride $(\mathrm{kg} / \mathrm{sec})$ \\
\hline NS8264 & B738 & CFM56-7B & 0.1160 & 1.70 & 17.90 & 17.60 \\
HU7577 & A320 & CFM56-5-A1 & 0.1011 & 1.40 & 28.40 & 4.80 \\
MU4405 & A321 & CFM56-5B1 & 0.1170 & 3.21 & 28.40 & 4.00 \\
MU5569 & A319 & CFM56-5B1 & 0.1170 & 3.21 & 17.60 & 4.60 \\
HU7817 & A320 & CFM56-5-A1 & 0.1011 & 1.40 & 17.90 & 4.00 \\
MU2158 & B738 & CFM56-7B & 0.1160 & 1.70 & 4.80 \\
\hline
\end{tabular}

TABLE 9: Pollutant emissions when aircraft uses multitarget taxi speed profiles.

\begin{tabular}{lccccc}
\hline Flight & Total taxi time $(\mathrm{s})$ & Total taxi fuel $(\mathrm{kg})$ & Hydrocarbon $(\mathrm{kg})$ & Oxycarbide $(\mathrm{kg})$ & Oxynitride $(\mathrm{kg})$ \\
\hline NS8264 & 416.1677 & 58.7583 & 82.0682 & 864.1306 & 231.7222 \\
HU7577 & 398.7802 & 47.3059 & 56.4433 & 709.5735 & 161.2667 \\
MU4405 & 467.7061 & 58.6528 & 175.6563 & 1554.094 & 1026.056 \\
MU5569 & 308.7926 & 33.5404 & 115.9732 & 460.3694 & 166.1922 \\
HU7817 & 258.7275 & 30.1691 & 36.6232 & 962.2688 & 104.6294 \\
MU2158 & 463.4313 & 61.1616 & 91.3886 & 258.0385 \\
\hline
\end{tabular}

TABle 10: Comparison of calculation results of pollutant discharge from Xi'an Xianyang Airport in the first half of 2019.

\begin{tabular}{lcccc}
\hline & $\begin{array}{c}\text { Average total taxi time } \\
(\mathrm{h})\end{array}$ & $\begin{array}{c}\text { Average total HC emission } \\
(\mathrm{kg})\end{array}$ & $\begin{array}{c}\text { Average total CO emission } \\
(\mathrm{kg})\end{array}$ & $\begin{array}{c}\text { Average total NO emission } \\
(\mathrm{kg})\end{array}$ \\
\hline $\begin{array}{l}\text { Actual total emission } \\
\begin{array}{l}\text { Total emission after } \\
\text { planning }\end{array}\end{array}$ & 57483.1961 & 49455.5698 & 628295.286 & 147500.244 \\
\hline
\end{tabular}

\section{Conclusion}

This article first considered the aircraft's taxi distance and the number of turns during taxiing and established an aircraft path optimization model with the shortest total taxi distance of the scene as the target. The improved $\mathrm{A}^{*}$ algorithm was used to solve the model to obtain the $\mathrm{P}$ shortest path from the starting node to the target node. Based on this, a multitarget speed profile model considering taxi time and fuel consumption was established. 
Heuristic search was used for each path producing an accurate velocity profile. Simulations were performed using real flight data. The results show that after the aircraft's taxiing path is optimized, the total taxiing distance and number of turns of the aircraft are reduced. Compared with the traditional optimization method that does not take into account the number of turns, the airport operation efficiency is improved. By considering different weights, the multitarget speed profile model generates a set of Paretooptimal speed profiles for the aircraft's taxi path to achieve high-precision planning of the aircraft's taxi path. The concept of maximum theoretical speed is added to the heuristic search process, which further simplifies the calculation. It is faster than other complicated algorithms that consider multiple factors, which is helpful for real-time air traffic control decisions. From the perspective of the environment, considering the taxi time of the $4 \mathrm{D}$ trajectory and the comparison and calculation of the pollutant emissions when the ground aircraft adopts different speed profiles, the accurate multitarget taxiing $4 \mathrm{D}$ trajectory is more helpful for energy saving and emission reduction and practical application value. Future research will increase the actual interference factors of the airport, comprehensively analyze the actual situation of airport inbound and outbound flights, dynamically adjust the taxi path of the aircraft and maintain the real-time nature of the system, and further optimize the algorithm to improve the performance of the algorithm.

\section{Data Availability}

The data used to support the findings of this study are included within the supplementary information file. The supplementary information file contains the raw data for the calculation (the three XLS data files) and the program in the Python environment.

\section{Conflicts of Interest}

The authors declare that they have no conflicts of interest.

\section{Acknowledgments}

This work was supported by the National Key R\&D Project (2016YFB0502405), the National Natural Science Foundation of China (71801215), and the Open Fund of China Civil Aviation Environment and Sustainable Development Research Center (Think Tank) (CESCA2019Y04).

\section{Supplementary Materials}

The supplementary information file contains the raw data for the calculation (the three XLS data files) and the program in the Python environment. File "Fattribute.xls": data of aircraft type, take-off weight, engine type and engine number, rated power, fuel flow rate $(7 \%)$, and fuel flow rate $(30 \%)$ of the six flights selected. File "distance.xls": the length from node 1 (the first column data) to node 22 (the second column data) is 13.335 meters (the third column data). File "fixed_data.xls": the sheet of node coordinate is the node coordinate from 1 to 170 . The sheet of turning is turning radius (the fourth column) determined by three points (the points in the first column, the points in the second column, and the points in the third column). The sheet of output is output data of the six flights. File "ks_visualization": the glide path calculation program in Python environment. (Supplementary Materials)

\section{References}

[1] V. M. María and C. A. Hall, "Modelling performance and emissions from aircraft for the aviation integrated modelling project," in Proceedings of the 47th AIAA Aerospace Sciences Meeting Including the New Horizons Forum and Aerospace Exposition, Orlando, FL, USA, January 2009.

[2] Y. Jung, "Fuel consumption and emissions from airport taxi operations," NASA Green Aviation Summit, vol. 110 pages, 2010.

[3] S. Ravizza, E. K. Atkin, and E. K. Burke, "A more realistic approach for airport ground movement optimisation with stand holding," Journal of Scheduling, vol. 17, no. 5, pp. 507-520, 2014.

[4] M. Weiszer, P. J. Chen, and P. Stewart, "A real-time active routing approach via a database for airport surface movement," Transportation Research Part C: Emerging Technologies, vol. 58, pp. 127-145, 2015.

[5] M. Weiszer, J. Chen, and P. Stewart, "Preference-based evolutionary algorithm for airport runway scheduling and ground movement optimisation," in Proceedings of the IEEE International Conference on Intelligent Transportation Systems, IEEE, Las Palmas, Spain, September 2015.

[6] N. Li and H. -z Lu, "Metthod to find out path of aircraft based on surface movement radar data," Aeronautical Computing Technique, vol. 46, no. 2, pp. 6-9, 2016.

[7] J. Chen, G. M. Weiszer, J. A. S. AtkinRavizza, and E. K. Burke, "Toward a more realistic, cost-effective, and greener ground movement through active routing: a multiobjective shortest path approach," IEEE Transactions on Intelligent Transportation Systems, vol. 17, no. 12, pp. 3524-3540, 2016.

[8] J. Stewart, M. Weiszer, and Z. Elham, "Multi-objective fuzzyrule-based prediction and uncertainty quantification of aircraft taxi time," in Proceedings 2017 IEEE 20th International Conference on Intelligent Transportation Systems (ITSC), Yokohama, Japan, October 2017.

[9] Z. Wang, J.-J. Xiong, and H. Chen, "A research on aircraft taxiing speed and fuel consumptio," Journal of Wuhan University of Technology (Transportation Science \& Engineering), vol. 41, no. 3, pp. 391-394, 2017.

[10] T. Zhang, M. Ding, H. Zuo et al., "An online speed profile generation approach for efficient airport ground movement," Transportation Research Part C: Emerging Technologies, vol. 93, pp. 256-272, 2018.

[11] X. Zhu, N. Li, Y. Sun, H. Zhang, K. Wang, and S.-B. Tsai, “A study on the strategy for departure aircraft pushback control from the perspective of reducing carbon emissions," Energies, vol. 11, no. 9, p. 2473, 2018. 